University of Wollongong

Research Online

Faculty of Engineering and Information

Faculty of Engineering and Information

Sciences - Papers: Part A

Sciences

$1-1-2013$

\title{
Effects of steel slag content and curing time on compressive strength of underwater compacted coal wash
}

\author{
Gabriele Chiaro \\ University of Wollongong, gchiaro@uow.edu.au \\ Buddhima Indraratna \\ University of Wollongong, indra@uow.edu.au \\ Cholachat Rujikiatkamjorn \\ University of Wollongong, cholacha@uow.edu.au \\ Shaghayegh Naeeni \\ University of Wollongong, sn907@uowmail.edu.au
}

Follow this and additional works at: https://ro.uow.edu.au/eispapers

Research Online is the open access institutional repository for the University of Wollongong. For further information contact the UOW Library: research-pubs@uow.edu.au 


\title{
Effects of steel slag content and curing time on compressive strength of underwater compacted coal wash
}

\author{
Abstract \\ The reclamation project at the Outer Harbor of Wollongong's Port Kembla, Australia, involves compaction \\ of a large volume of granular fill material either under submerged or dry conditions. Due to environmental \\ concerns (e.g. lack of suitable landfill space to dispose industrial wastes, conservation of natural \\ resources etc) and the large volume reclamation project, Port Kembla Port Corporation is considering the \\ use of locally abundant granular wastes of coal wash (CW) and steel furnace slag (SFS) as an alternative \\ to conventional and costly fill materials. Although numerous studies have been reported on the \\ geotechnical characterization of granular industrial wastes, only few information is available to \\ comprehensively describe their compressive and mechanical behavior under submerged conditions. This \\ paper reports on results of a series of unconfined compression strength (UCS) tests performed to \\ investigate the effects of SFS content and curing time on the strength properties of underwater \\ compacted mixtures of CW and SFS. For various mixtures kept submerged in seawater for a curing time \\ of 7, 14 and 28 days, it was found that UCS strength properties increase with SFS content and

\section{Keywords} \\ time, compressive, strength, underwater, compacted, coal, wash, steel, effects, slag, content, curing

\section{Publication Details} \\ Chiaro, G., Indraratna, B., Rujikiatkamjorn, C. \& Naeeni, S. (2013). Effects of steel slag content and curing \\ time on compressive strength of underwater compacted coal wash. In B. Indraratna, C. Rujikiatkamjorn \& \\ J. S. Vinod (Eds.), The International Conference on Ground Improvement \& Ground Control (pp. \\ 1617-1622). Singapore: Research Publishing.
}




\title{
EFFECTS OF STEEL SLAG CONTENT AND CURING TIME ON COMPRESSIVE STRENGTH OF UNDERWATER COMPACTED COAL WASH
}

\author{
Gabriele Chiaro $^{a}$, Buddhima Indraratna ${ }^{b}$, Cholachat Rujikiatkamjorn $^{c}$ \\ and Shaghayegh Naeeni ${ }^{d}$ \\ Centre for Geomechanics and Railway Engineering, School of Civil, \\ Mining and Environmental Engineering, University of Wollongong 2522, \\ NSW, Australia.E-mail: ${ }^{a}$ gchiaro@uow.edu.au, ${ }^{b}$ indra@uow.edu.au, \\ ccholacha@uow.edu.au,dsn907@uow.edu.au
}

\begin{abstract}
The reclamation project at the Outer Harbor of Wollongong's Port Kembla, Australia, involves compaction of a large volume of granular fill material either under submerged or dry conditions. Due to environmental concerns (e.g. lack of suitable landfill space to dispose industrial wastes, conservation of natural resources etc) and the large volume reclamation project, Port Kembla Port Corporation is considering the use of locally abundant granular wastes of coal wash (CW) and steel furnace slag (SFS) as an alternative to conventional and costly fill materials. Although numerous studies have been reported on the geotechnical characterization of granular industrial wastes, only few information is available to comprehensively describe their compressive and mechanical behavior under submerged conditions. This paper reports on results of a series of unconfined compression strength (UCS) tests performed to investigate the effects of SFS content and curing time on the strength properties of underwater compacted mixtures of $\mathrm{CW}$ and SFS. For various mixtures kept submerged in seawater for a curing time of 7,14 and 28 days, it was found that UCS strength properties increase with SFS content and curing time, while volumetric expansion became insignificant within one week.
\end{abstract}

Keywords: Coal wash, Compressive strength, Steel furnace slag, Submergence.

\section{INTRODUCTION}

In New South Wales, Australia, coal mining and steel industry produce several million tons per year of granular wastes. The scarcity of suitable landfill space for waste stockpiles and the shortage of natural earth aggregates highlight the necessity of finding innovative ways of reusing and recycling these industrial by-products. Thus, the use of locally available granular wastes, such as coal wash (CW) and steel furnace slag (SFS), as reclamation fill for the offshore expansion at the existing Outer Harbor of Port Kembla near Wollongong, would be an effective way of disposing of these wastes and reducing the demand for quarried fresh aggregates and dredged marine sand. 
The improvement of geotechnical properties of coal mine wastes has been conducted in the past (Indraratna et al. 1994, Kamon 1997, Pusadkar and Ramaswamy 2005). However, to date there has been no study on the compaction and shear strength properties of mixtures of CW and SFS, neither under dry or submerged conditions. Such study is fundamental for identifying a suitable port reclamation fill composed of granular blended wastes. Chemical stabilization is a suitable method for improving the bearing capacity and the strength of compacted CW, as shown by Okagbue and Ochulor (2007) who investigated the effectiveness of ordinary Portland cement (OPC) in the stabilization of Nigerian coal reject. On the other hand, Poh et al. (2006), using SFS fines as a chemical additive for fine-grained (cohesive) soils, reported that at least 15-20\% of SFS fines with a long curing period may be required in order to show a remarkable improvement in terms of unconfined compression strength $\left(q_{u}\right)$, swelling behavior and durability. According to Shi (2004), the chemical composition and mineralogy of SFS is similar to that of OPC. Therefore, similar to pozzolanic materials, SFS is expected to form strength-enhancing products while reacting spontaneously with water. Yet, the potential of SFS as stabilizer for improving the compressive strength of CW, especially in the presence of seawater, has not been studied.

Recycling of industrial wastes is environmentally prudent. Nevertheless, the rational evaluation and quantification of its construction potential as an effective port reclamation fill offers a significant challenge, considering the material heterogeneity, its vulnerability to breakage and collapse, and the lack of knowledge of its performance under submerged loading conditions. In view of these considerations, the objective of this paper is to evaluate the coupled effects of SFS content and curing period on the unconfined compression strength (UCS) properties of various CW-SFS mixtures compacted under submergence.

\section{TEST MATERIAL AND PROCEDURE}

The CW used in this study is a by-product of coal mining operations produced by the coal washery process. SFS is produced in a Basic Oxygen Furnace (BOF) as by-product of the steelmaking process. The geotechnical index properties of tested CW and SFS samples are listed in Table 1. The gradation curves are shown in Figure 1.

Three mixtures, namely S10C90 (90\% CW + 10\% SFS), S25C75 (75\% CW + 25\% SFS) and S50C50 (50\% CW + 50\% SFS), were prepared by varying the percentage in weight of ovendried CW to oven-dried SFS. Cylindrical specimens having a diameter of $203 \mathrm{~mm}$ and a height of $406 \mathrm{~mm}$ were compacted into a $14 \mathrm{~L}$ split-mould under submergence in seawater using an electric vibrating hammer (Figure 2). The soil was compacted in several layers until there was no further significant volumetric decrease. Specimens were kept submerged

Table 1. Summary of geotechnical index properties of tested CW and SFS samples.

\begin{tabular}{lcccc}
\hline Material & $\mathrm{G}_{s}$ & $\mathrm{C}_{c}$ & $\mathrm{C}_{u}$ & $\mathrm{D}_{50}(\mathrm{~mm})$ \\
\hline $\mathrm{CW}$ & 2.13 & 1.02 & 10.2 & 2.3 \\
$\mathrm{SFS}$ & 3.48 & 1.03 & 5.2 & 1.8 \\
$G_{s}$ : specific gravity; $C_{c}$ : coefficient of curvature; \\
$\mathrm{C}_{u}$ : coefficient of uniformity ; $\mathrm{D}_{50}$ : mean diameter \\
\hline
\end{tabular}




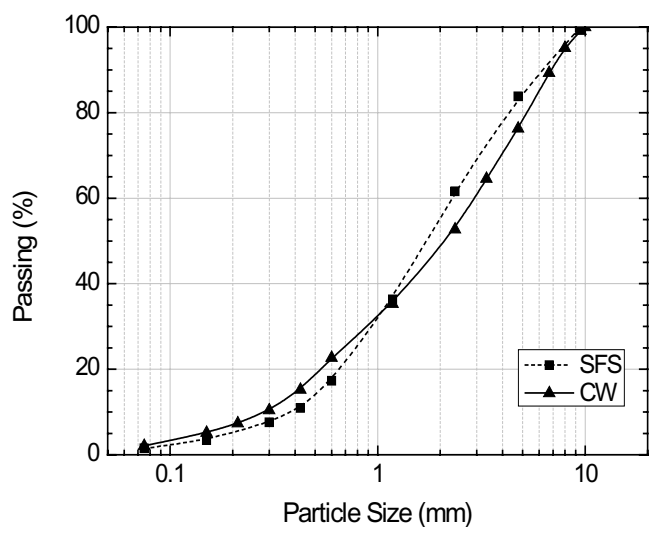

Figure 1. Particle size distribution curves for SFS and CW.
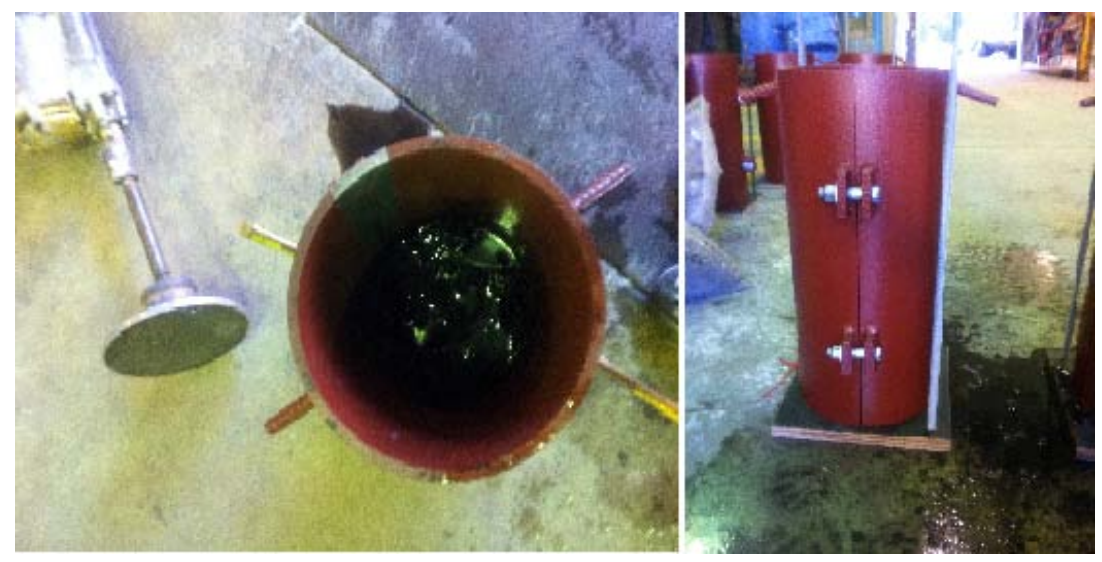

Figure 2. Vibrating hammer and split compaction mould used in this study.

in seawater for 7, 14 and 28 days. To prevent the effect of curing temperature on strength development of $\mathrm{CW}$ (i.e. an increase in temperature accelerates the hydration process), specimens were cured in a controlled temperature room $\left(20^{\circ}\right)$. Swelling behavior (i.e. onedimensional expansion) was measured on a daily basis. At the end of the curing period, the specimens were dried for 24 hours. Finally, to investigate the strength increase of CW mixes to SFS, unconfined compression tests were performed at a constant rate of $1 \mathrm{~mm} / \mathrm{min}$.

\section{UNCONFINED COMPRESSION TEST RESULTS}

Figure 3 shows the results of UCS tests performed on the CW-SFS mixtures. Typical strength behavior of untreated $\mathrm{CW}$ specimen compacted under submergence is also reported for comparison. The $q_{u}$ value of $\mathrm{CW}$ compacted under submergence is on the order of $10 \mathrm{kPa}$. In the case of $100 \% \mathrm{CW}$ specimens, it is expected that no significant strength improvement occurs with time. When CW is mixed with 10\% SFS (i.e. S10-C90 mixture), a modest gain in strength can be observed. The $q_{u}$ value is $20 \mathrm{kPa}$ after 7 days 

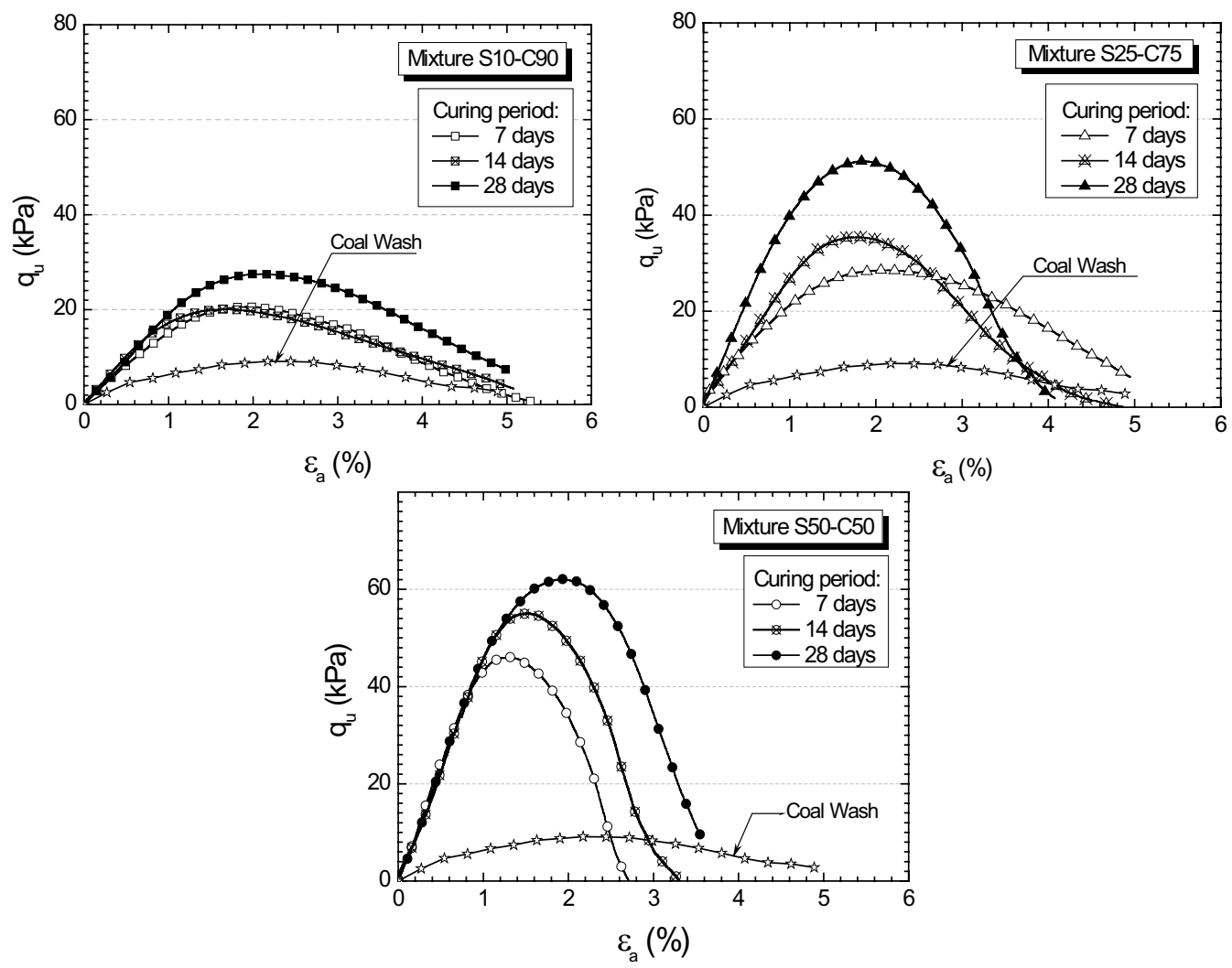

Figure 3. Stress-strain relationships of CW-SFS mixture cured in seawater for 7,14 and 28 days.

and then increases to $27 \mathrm{kPa}$ within 28 days. Thus, after 28 days curing time in seawater, the shear strength of CW stabilized with $10 \%$ SFS is almost 3 times more than that of $100 \%$ CW.

By further increasing the SFS content up to $25 \%$ and 50\%, to produce S25-C75 and S50-C50 mixtures, respectively, an additional and significant increase in strength could be observed. After 28 days of curing, the strength of the S25-C75 mixture is almost 5 times higher than that of $100 \% \mathrm{CW}$, while in the case of the S50-C50 mixture, the strength increases 6.3 times.

These test results clearly show that CW when stabilized with SFS has much higher shear strength. The strength increases with increasing curing period in seawater, however, the extent and the rate of strength development vary significantly with the percentage of SFS in the mixture, as shown by Figure 4 .

\subsection{Swelling/Volumetric Expansion Behavior}

Figure 5 reports the observed swelling behavior evaluated by one-dimensional expansion tests. A significant volumetric expansion could be observed during the first four to five days. This behavior can be associated with the hydration of free lime $(\mathrm{CaO})$ and free magnesium $(\mathrm{MgO})$, that react with water to form $\mathrm{Ca}(\mathrm{OH})_{2}$ and $\mathrm{Mg}(\mathrm{OH})_{2}$. After this time, the 


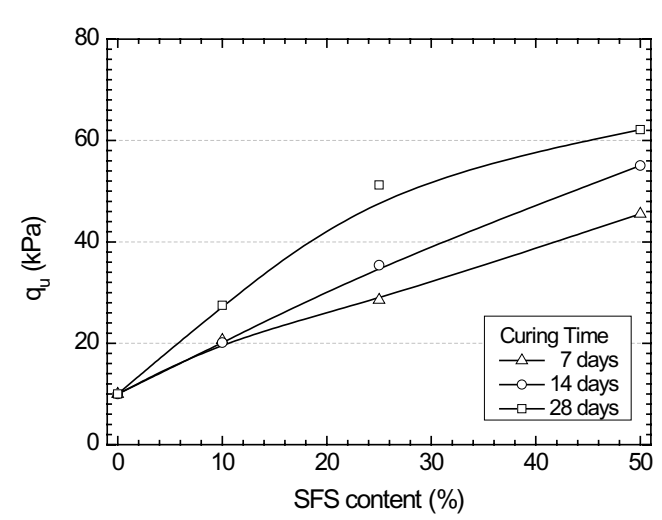

Figure 4. Effect of slag content and curing period on strength of CW-SFS mixtures.

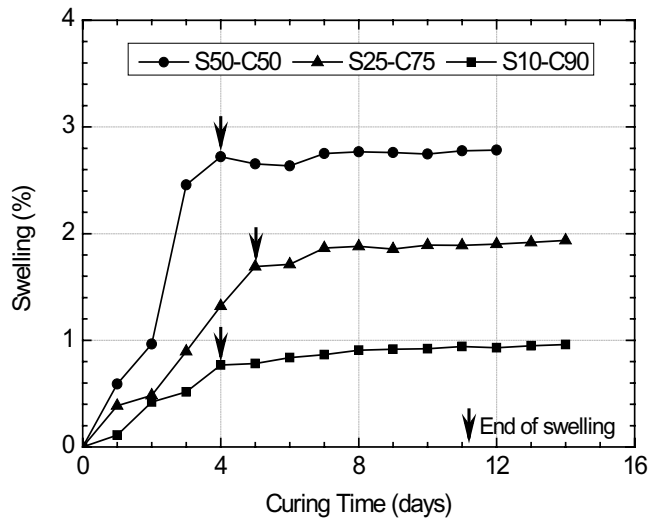

Figure 5. Effect of slag content on the swelling behavior of CW-SFS mixtures cured in seawater.

development of swelling is negligible and independent from the amount of SFS in the mixture. The maximum value of swelling increases from $\sim 1 \%$ to $\sim 3 \%$ with an increase in SFS content from $10 \%$ to $50 \%$. These test results prove that swelling/expansion of CW-SFS mixtures do not represent a critical issue since the construction period of port reclamation is significantly longer than a week.

\section{DISCUSSION}

It is recognized that the type, quality and quantity of stabilizer have different effects on the strength development of treated soil. In the case of SFS used in this current study and produced in a $\mathrm{BOF}$, the presence of chemical constituents like free lime $(\mathrm{CaO})$ and free magnesium $(\mathrm{MgO})$ ensures good hydration properties for the SFS in the short- and long-term, respectively. On the other hand, active compounds such as tricalcium silicate $\left(\mathrm{C}_{3} \mathrm{~S}\right)$, dicalcium silicate $\left(\mathrm{C}_{2} \mathrm{~S}\right)$, tetracalcium aluminoferrite $\left(\mathrm{CA}_{3} \mathrm{~F}\right)$ and dicalcium ferrite $\left(\mathrm{C}_{2} \mathrm{~F}\right)$ provide cementitious properties to the SFS (Wang and Yan, 2010). Therefore, strength development as observed from UCS tests, can be attributed to the active compounds in SFS, i.e. through hydration in seawater, these active compounds crystallize and bind together the CW and SFS particles. In other words, SFS acts as a binder and provides the much desirable geotechnical properties of mixtures with increasing curing time.

\section{CONCLUSIONS}

The evaluation of the construction potential of CW-SFS mixtures as an effective port reclamation fill offers a significant challenge considering the material heterogeneity and its performance under submerged loading conditions as shown by this study. Test results indicate a significant improvement in the strength of CW when stabilized with SFS. The unconfined compressive strength of the mixture increases with the curing period in seawater. However, the extent and rate of strength development vary significantly with the percentage of SFS in the mixture. After 28 days curing time, CW-SFS mixture strengths are 3, 5 and 6 times greater than that of CW alone when mixed with $10 \%, 25 \%$ or $50 \%$ SFS, respectively. 
Strength development, as observed from UCS tests, can be attributed to the hydration in seawater with the active compounds crystallize binding the CW and SFS particles together. Thus, SFS acts as a binder and provides favorable geotechnical properties of mixtures. Even though hydration of $\mathrm{CaO}$ and $\mathrm{MgO}$ produces a modest volumetric expansion of $\mathrm{CW}$ specimens, it ceases within a week. Therefore, volumetric expansion should not represent a critical issue during the construction of port reclamation.

It is noted that the results presented in this paper are only indicative and not applicable to all types of CW-SFS mixtures since the geotechnical properties of CW-SFS blends may vary significantly depending on the source and manufacturing process of CW and SFS. In addition, while these laboratory results support the use of CW and SFS as a structural fill, additional laboratory and field investigation are necessary to verify the actual performance of these waste materials when used as submerged fill for port reclamation works.

\section{ACKNOWLEDGEMENTS}

The authors gratefully acknowledge the financial assistance from the Australia Research Council and Port Kembla Port Corporation, and the support of Andrew Dunne and Tonnilee Andrew (PKPC), Dr Jayantha Ameratunga and John Thompson (Coffey Geotechnics), Geoff McIntosh (Douglas Partners), Carl Ernst (BHP Billiton-Illawarra Coal), Marc Smith (ASMS) and Daniel Berthier (Menard Bachy). The authors also thank BHP BillitonIllawarra Coal for providing CW and Australian Steel Mill Services (ASMS) for providing SFS needed for this study.

\section{REFERENCES}

1. Indraratna, B., Gasson, I. and Chowdhury, R.N. (1994). Utilization of compacted coal tailings as structural fill, Can. Geotech. J., 31(4): 614-623.

2. Kamon, M. (1997). Geotechnical utilisation of industrial wastes, Proc. $2^{\text {nd }}$ International Congress on Environmental Geotechnics, Osaka, Japan: 1293-1309.

3. Okabue, C.O. and Ochulor, O.H. (2007). The potential of cement-stabilize coal-reject as construction material, Bul. Eng. Geol. Environ., 15(2): 143-151.

4. Poh, H. Y., Ghataora, G. S. and Ghazireh, N. (2006). Soil Stabilization Using Basic Oxygen Steel Slag Fines, J. Mater. Civil Eng., ASCE, 18(2): 229-240.

5. Pusadkar, S.S. and Ramaswamy, G. (2005). Collapse behavior of compacted coal ash fill, Geotech. Test. J. ASTM, 28(3): 1-8.

6. Shi, C. (2004). Steel slag - Its production, processing, characteristics, and cementitious properties J. Mater. Civil Eng., ASCE, 16(3): 230-236.

7. Wang, Q. and Yan, P. (2010). Hydration properties of basic oxygen furnace steel slag, Constr. Build. Mater., 24(7): 1134-1140. 